\title{
Multiobjective Joint Economic Dispatching of a Microgrid with Multiple Distributed Generation
}

\author{
Hui Hou ${ }^{1}$, Mengya Xue ${ }^{1}{ }^{*}$, Yan $\mathrm{Xu}^{2}{ }^{2}$, Jinrui Tang ${ }^{1}{ }^{10}$, Guorong $\mathrm{Zhu}{ }^{1}$, Peng Liu ${ }^{1}$ and Tao Xu ${ }^{1}$ \\ 1 School of Automation, Wuhan University of Technology, Wuhan 430070, Hubei, China; \\ houhui@whut.edu.cn (H.H.); tangjinrui@whut.edu.cn (J.T.); zhgr_55@whut.edu.cn (G.Z.); \\ liupengfight94@163.com (P.L.); xutaoLBJ@163.com (T.X.) \\ 2 School of Electrical and Electronic Engineering, Nanyang Technological University, Singapore 637551, \\ Singapore; xuyan@ntu.edu.sg \\ * Correspondence: xuemengya_xmy@163.com; Tel.: +86-177-6409-8141
}

Received: 28 October 2018; Accepted: 20 November 2018; Published: 23 November 2018

check for updates

\begin{abstract}
Based on the operation characteristics of each dispatch unit, a multi-objective hierarchical Microgrid (MG) economic dispatch strategy with load level, source-load level, and source-grid-load level is proposed in this paper. The objective functions considered are to minimize each dispatching unit's comprehensive operating cost (COC), reduce the power fluctuation between the MG and the main grid connect line, and decrease the remaining net load of the MG after dispatch by way of energy storage (ES) and clean energy. Firstly, the load level takes electric vehicles (EVs) as a means of controlling load to regulate the MG's load fluctuation using its energy storage characteristics under time-of-use (TOU) price. Then, in order to minimize the remaining net load of the MG and the COC of the ES unit through Multiobjective Particle Swarm Optimization (MPSO), the source-load level adopts clean energy and ES units to absorb the optimized load from the load level. Finally, the remaining net load is absorbed by the main grid and diesel engines (DE), and the remaining clean energy is sold to the main grid to gain benefits at the source-grid-load level. Ultimately, the proposed strategy is simulated and analyzed with a specific example and compared with the EVs' disorderly charging operation and MG isolated grid operation, which verifies the strategy's scientificity and effectiveness.
\end{abstract}

Keywords: Microgrid; economic dispatch; distributed generation; Multiobjective Particle Swarm Optimization; Electrical Vehicle

\section{Introduction}

With the increasing global resource scarcity and ecological pollution, the Microgrid (MG), as an effective means of supplementing main grid operation, has been more and more favored by the world [1]. MG economic dispatch [2,3] is one of the key contents of MG-related research. The purpose is to rationally distribute the output of each unit and maximize economic benefits, environmental benefits, or other indicators under the premise of meeting the normal demand of all loads.

At present, domestic and international MG economic dispatch research focuses strongly on single-objective optimization scheduling. An economic dispatching model with the minimum investment and maintenance cost of the MG is established in [4,5] and solved by the reduced gradient method, while the operation constraints of the distributed unit are simplified. Although the author simplifies the simulation calculation process, the results lack practical significance. In [6], the MG economic scheduling problem is transformed into a mixed-integer linear programming problem by a linearization method. This method can quickly solve the short-term economic dispatch problem of an MG, but the solution effect for a long-term or multiobjective economic dispatching problem of the MG will be greatly reduced. Other improved intelligent algorithms have been used to solve the established 
single-objective economic dispatching model of an MG and compare it with the corresponding basic algorithm to verify the superiority of the algorithm used [7-9].

On the other hand, some scholars have studied the multiobjective economic dispatching problem of MGs and taken into account other factors, such as the environmental benefits. A multiobjective economic dispatching model for a cogeneration MG with heating benefits taken into account is presented in [10], and the multiobjective problem was transformed into a nonlinear single-objective optimization problem through the maximum fuzzy satisfaction method [11]. However, the membership functions used in the model depend mostly on practical experience, so the reliability of the optimization results might be reduced. In [12], the NSGA-II algorithm was used to solve the multiobjective MG economic dispatch problem with minimum operation cost and load reduction index. Considering that electric vehicles (EVs) as mobile loads have energy storage (ES) characteristics, many scholars introduce EVs into the MG economic dispatch and use their ES characteristics to stabilize fluctuations in the MG. Reference [13] uses orderly charging and discharging behavior of EVs to cut peaks and fill valleys in the MG load to a certain extent. However, the number of EVs introduced is small, and only a group of weights are simply selected to transform the multiobjective economic dispatch of an MG into a single-objective problem, so the optimized results are lacking in persuasion. Reference [14] introduces the concept of an "unbalance rate" into the load of the MG, issues the corresponding electricity price information according to the fluctuation of the current unbalance rate, and fully mobilizes EVs to participate in the MG economic dispatch.

In summary, whether it is single-objective or multiobjective economic dispatch of an MG, there are similar problems, such as limited objective functions, uncomprehensive consideration of the distributed generation (DG) operation characteristics, and somewhat inconsistent results with production practice. Therefore, this paper proposes a multiobjective and hierarchical joint economic dispatching strategy for an MG and the main grid which transforms the economic dispatching problem of the MG into a three-level optimization problem with load level, source-load level, and source-grid-load. Each level fully considers the operational characteristics of the participating dispatching units, then establishes corresponding objective functions, for instance, including minimizing each dispatching unit's comprehensive operating cost (COC), reducing the power fluctuation between the MG and the main grid connect line, and decreasing the remaining net load rate of the MG after dispatch by ES and clean energy. Finally, the proposed strategy is simulated and analyzed with a specific example and compared with the EV disorderly charging operation and MG isolated grid operation, which verifies the strategy's scientificity and effectiveness.

The main contribution of this work lies in two aspects. One is that the traditional MG economic dispatching process is divided into three levels, namely, load level, source-load level, and source-grid-load level in this paper. Each level has its own specific unit to participate in the operation, and the objective function of each level changes with the different operating units involved. The characteristic of this operation strategy is that it can be beyond the content discussed in this paper and can be changed according to the needs of decision-makers. For example, if an MG system needs to consider CHP (Combined Heat and Power), the load level needs to consider the demand of heat load and the economic cost of thermal energy generators, and the source-load level and source-grid-load level also need to make corresponding changes. The other is the diversity and continuity of the methods for solving the proposed strategy. The Monte Carlo simulation algorithm is used to obtain the result that satisfies the demand of the load level, and the result is substituted into the source-load level as a known condition. The source-load level uses the MPSO algorithm to find a series of Pareto Fronts; then, the fuzzy membership function is used to evaluate these solutions comprehensively, and the solution with the highest satisfaction is selected as the optimal solution. Finally, the optimal solution is substituted into the source-grid-load level as a known condition, and the whole scheduling process is completed by repeating the solving process of the source-load level. Overall, this work makes an initial effort to design and implement a multiobjective hierarchical joint economic dispatching strategy 
for MGs. This strategy achieves different optimization objectives according to the different dispatching units involved at each level, which provides a new idea for solving those similar problems.

The rest of the paper is organized as follows. In Section 2, the joint economic dispatch strategy for an MG with the main grid is introduced in detail, and the models of the load level, the source-load level, and the source-grid-load level are built. In Section 3, the detailed solution methods and solution procedures of the proposed strategy are described. In Section 4, the simulation and an analysis of the results are discussed. Section 5 presents the conclusions.

\section{Joint Economic Dispatch Strategy for MGs and the Main Grid}

\subsection{The MG System Model with Multiple DGs}

The MG system that contains wind turbines (WT), photovoltaics (PV), diesel engines (DE), ES, and EVs are shown in Figure 1. The mathematic model of the WT, PV, DE, and ES unit in the system is shown in [15], and that of EV is shown in [16].

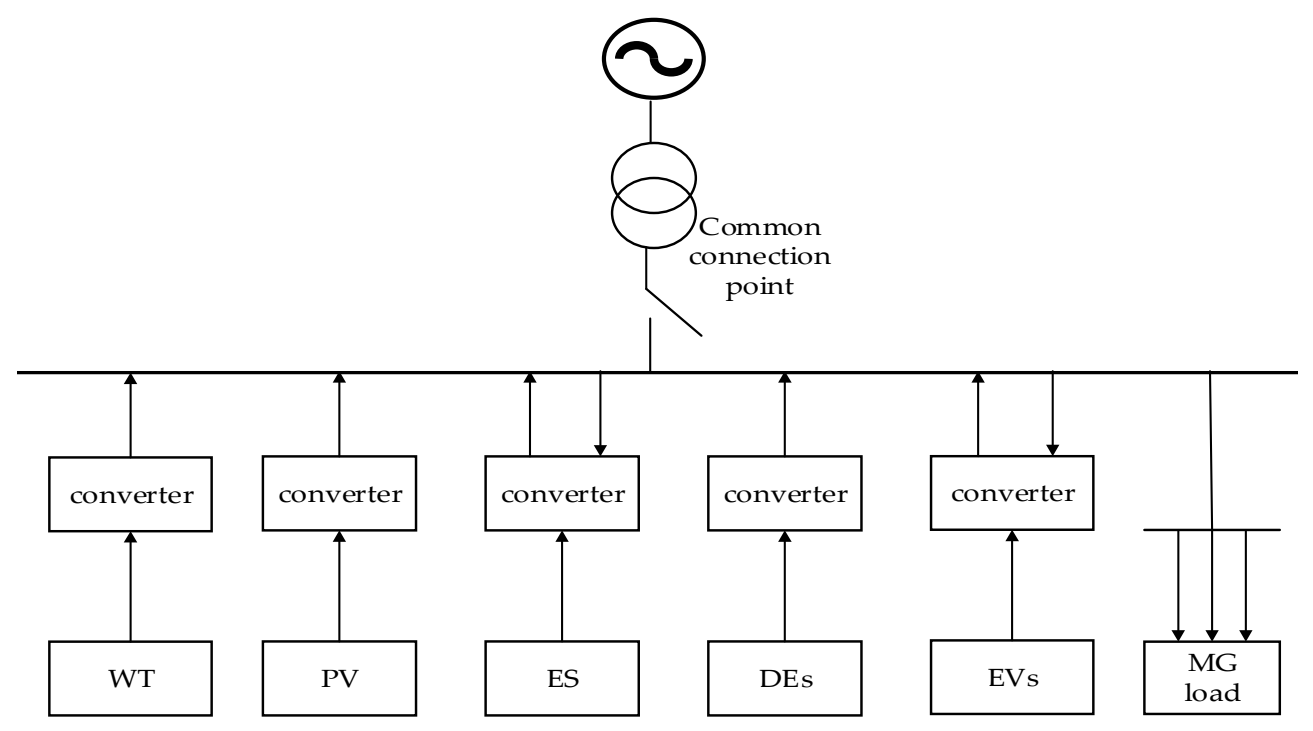

Figure 1. Structure diagram of the Microgrid (MG) system.

\subsection{Strategy Overview}

In this paper, a multiobjective hierarchical dispatching strategy is adopted for the joint economic dispatch of EVs, an MG, and the main grid. The strategy divides the entire scheduling process into three levels: load level, source-load level, and source-grid-load level.

Considering the randomness of the charging behavior of a large number of EVs and the owners' driving habits, the charging and discharging behavior of EVs is reasonably arranged at the load level under the background of TOU price so as to reduce the load fluctuation of the MG and the charging cost of EV users. Based on the MG optimized load obtained from the load level, the source-load level gives priority to the use of clean energy, such as WT and PV, to maximize the consumption of the MG optimized load. Then, it makes full use of the ES unit's dispatching capacity in order to minimize the net load ratio of the MG after dispatching and the COC of the ES unit. Under the premise of obtaining the net load data after the source-load level scheduling, the source-grid-load level takes main grid connect-line power fluctuation and the COC of DEs and connect-line power into account. The output of DEs and main grid connect-line power are reasonably arranged, thus achieving the dual benefits of economic and secure operation of the MG and the main grid. The structure of the multiobjective and hierarchical MG economic dispatch strategy is shown in Figure 2. 


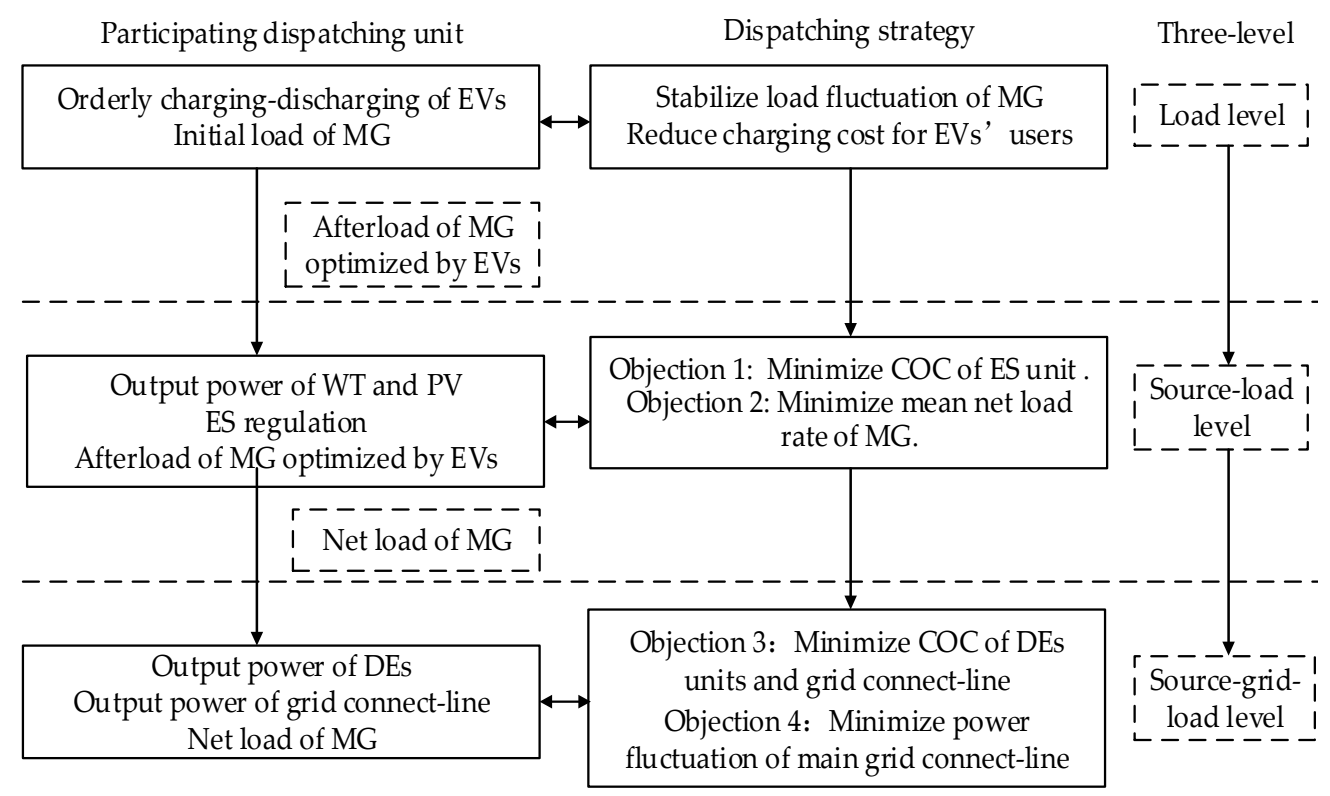

Figure 2. Structure of the multiobjective and hierarchical MG economic dispatch strategy.

\subsection{Dispatch Strategy for the Load Level}

The load level mainly deals with the orderly dispatching of large-scale EVs in the MG system. As a moving load, an EV has the dual characteristics of load and ES. According to the driving habits of EV users, reasonable arrangement of charging and discharging scheduling for EVs can not only reduce the cost of charging and obtain discharging benefits, but also stabilize the peak-valley difference in the load. It is known that the return time of the last journey of an EV satisfies the normal distribution $t_{0} \sim N(17.6,3.4)$, and the travel distance $s$ approximately obeys the lognormal distribution in [17]

$$
f_{s}(s)=\frac{1}{s \sigma_{s} \sqrt{2 \pi}} e^{\frac{-\left(\ln s-\mu_{s}\right)^{2}}{2 \sigma_{s}}}
$$

where $s$ is the daily travel distance of the EV; $\mu_{s}$ is the expectation of the EV's daily travel distance, which has a value of 3.2; $\sigma_{s}$ is the standard deviation of the EV's daily travel distance, which has a value of 0.88 ; and $f_{s}(s)$ is the probability density function of the EV's daily travel distance.

The probability density curve of the EV's daily travel distance is shown in Figure 3.

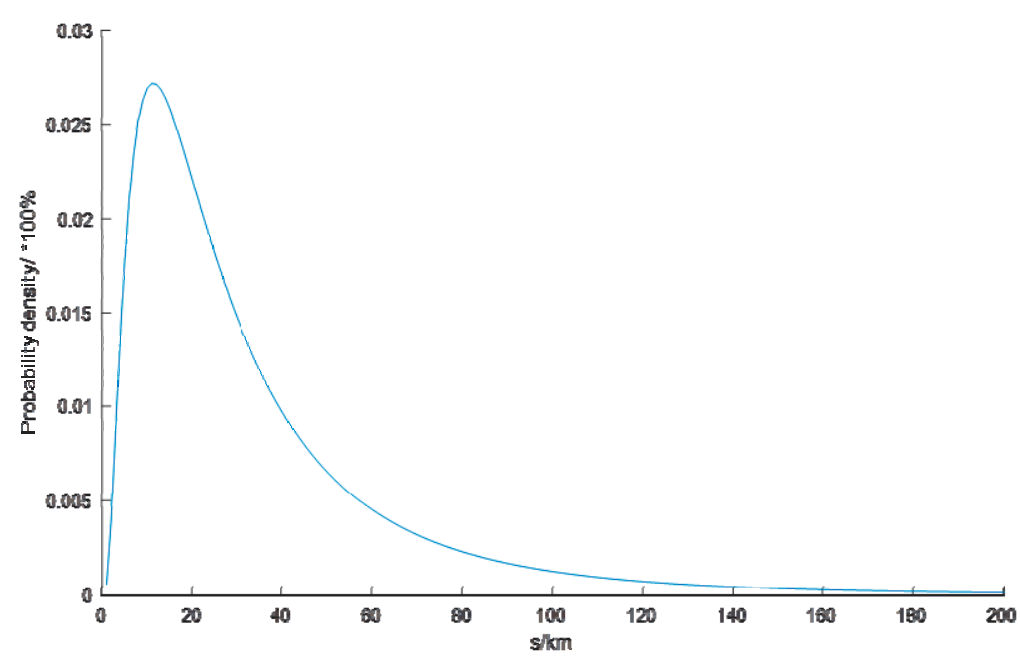

Figure 3. Probability density curve of an EV's daily travel distance. 
According to the peak and valley states of the MG load, the return time and travel distance of the EV users, some parameters including the starting and ending time, and the duration of the EVs' charging and discharging are determined [18]. The dispatching strategy of EVs at the load level is shown in Figure 4.

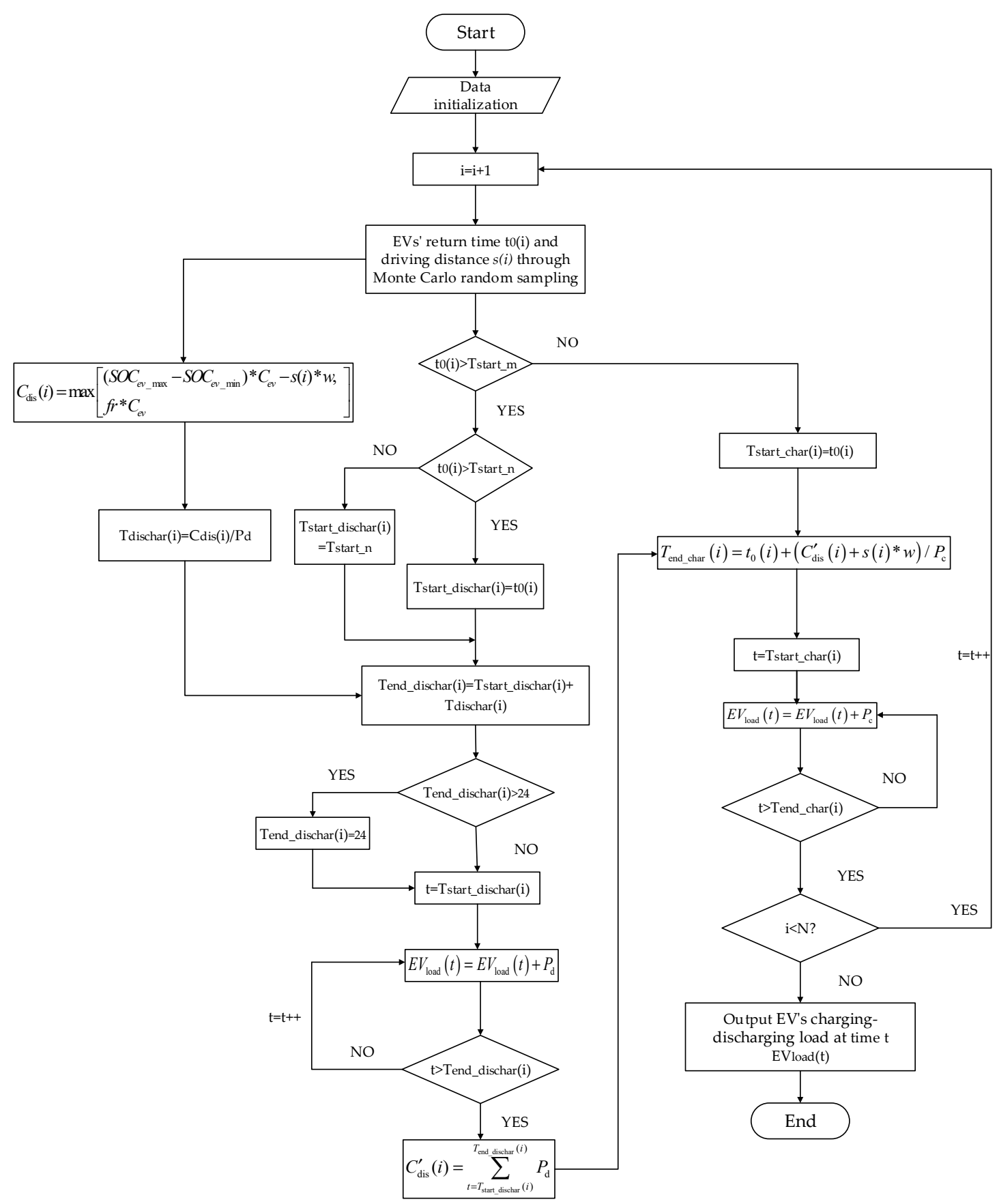

Figure 4. A flow chart of dispatching strategy of EVs at the load level.

The initial input information in Figure 4 is as follows: $N$ is the number of EVs, $P_{c}$ is the EV's charging power, $P_{d}$ is the EV's discharging power, $w$ is the EV's power consumption per kilometer, $f r$ is the EV's maximum discharging depth, $S O C_{e v_{-} \text {min }}$ and $S O C_{e v_{-} \max }$ are, respectively, the upper and lower limit of the EV's state of charge (SOC), $C_{e v}$ is battery capacity, and $T_{\text {start_m }}$ and $T_{\text {start_n }}$ are, respectively, the early and late peak start time of the MG load. We set the EV's charging-discharging load $E V_{\text {load }}(t)$, the counter $i$, and $t$ to zero. 
The meanings of the variables that appear in Figure 4 are as follows: $s(i)$ and $t_{0}(i)$ are, respectively, the daily travel distance and daily travel return time of EV $i$, which are all generated by Monte Carlo stochastic simulation; $C_{\mathrm{dis}}(i)$ and $C_{\mathrm{dis}}^{\prime}(i)$ are the theoretical maximum discharging capacity and the actual maximum discharging capacity of EV $i$, respectively; $T_{\text {start_char }}(i)$ and $T_{\text {end_char }}(i)$ are, respectively, the start-charging time and end-charging time of EV $i ; T_{\text {start_dischar }}(i)$ and $T_{\text {end_dischar }}(i)$ are, respectively, the start-discharging time and end-discharging time of EV $i$; $T_{\text {dischar }}(i)$ is the actual maximum discharging duration of $\mathrm{EV} i$; and $E V_{\text {load }}(t)$ is the EVs' charging-discharging load, which changes with change in time $t$.

\subsection{Dispatch Strategy for the Source-Load Level}

The objective function of the source-load level scheduling strategy minimizes the COC of the ES unit $f_{1}$ and average load rate $f_{2}$ :

$$
\begin{gathered}
f_{1}=\min \left[C_{\mathrm{ES} \_c o s t}\right] \\
f_{2}=\min \left[\left(\sum_{t=1}^{T} P_{\text {load }}^{\prime}(t) / P_{\text {load }}(t)\right) / T\right] \\
C_{\text {ES_cost }}=\left\{\begin{array}{c}
C_{\text {ES_om }}=\left|P_{\mathrm{ES}}(t)\right| * K_{\text {om_ES }} \\
C_{\text {ES_loss }}=n_{B} * C_{\text {loss }} \\
C_{\text {ES_price }}=\sum_{t=1}^{T}\left(P_{E S}(t) * \text { price }(t)\right)
\end{array}\right. \\
C_{\text {loss }}=\frac{C_{\text {cost_change }}\left(S O C_{\max }-S O C_{\text {min }}\right)}{n_{B N}} \\
P_{\text {load }}^{\prime}(t)=-P_{\text {pv }}(t)-P_{\mathrm{wt}}(t)+P_{\mathrm{ES}}(t)+P_{\text {load }}(t) \\
P_{\text {load }}(t)=P_{\text {load }}^{0}(t)+E V_{\text {load }}(t)
\end{gathered}
$$

where $C_{\mathrm{ES}}$ cost is the $\mathrm{COC}$ of ES, which includes operation and maintenance cost $C_{\mathrm{ES} \_o m}$, charging and discharging conversion loss $C_{\mathrm{ES} \_l o s s}$, and a small amount of charging $C_{\mathrm{ES} \_ \text {price; }} ; P_{\mathrm{ES}}(t), P_{\mathrm{pv}}(t)$, and $P_{\mathrm{wt}}(t)$ are, respectively, the power outputs of ES, PV, WT at time $t ; P_{\text {load }}(t)$ is the MG load at time $t$ after load level optimization; $P_{\text {load }}^{\prime}(t)$ is the net load of the MG at time $t ; P_{\text {load }}^{0}(t)$ is the original load of the MG system; and $E V_{\text {load }}(t)$ is the EVs' charging-discharging load, which is obtained by the load level.

$K_{\text {om_ES }}$ is the operation cost coefficient of the ES unit; $C_{\text {loss }}$ and $C_{\text {cost_change }}$ are, respectively, the battery loss cost caused by the charge-discharge state change of the ES unit and the replacement cost of the ES unit; $S O C_{\max }$ and $S O C_{\min }$ are the maximum and minimum SOC of the ES unit; and $n_{B}$ and $n_{\mathrm{BN}}$ are, respectively, the number of charge-discharge conversions in one cycle and the rated charge-discharge number in a life cycle.

The constraint conditions for ES units are

1. The SOC of ES unit constraint:

$$
S O C_{\max } \leq S O C(t) \leq S O C_{\min }
$$

2. Upper and lower output limit of ES power output:

$$
P_{\mathrm{ES}}^{\min } \leq P_{\mathrm{ES}}(t) \leq P_{\mathrm{ES}}^{\max }
$$

where $P_{\mathrm{ES}}^{\max }$ and $P_{\mathrm{ES}}^{\min }$ are, respectively, the maximum and minimum power output of the ES unit. 


\subsection{Dispatch Strategy for the Source-Grid-Load Level}

The objective function of the source-grid-load level dispatching strategy minimizes the COC for DE and main grid connect-line power $f_{3}$ and the power fluctuation of connect-line power $f_{4}$ :

$$
\begin{aligned}
& f_{3}=\min \left[C_{\text {de_cost }}+C_{\text {grid_cost }}\right] \\
& f_{4}=\min \left[\sum_{t=1}^{T-1}\left|P_{\text {grid }}(t+1)-P_{\text {grid }}(t)\right|\right] \\
& C_{\text {de_cost }}=\left\{\begin{array}{c}
C_{\text {de_om }}=\sum_{t=1}^{T} K_{o m \_d e} * P_{\text {de }}(t) \\
C_{\text {de_en }}=\sum_{t=1}^{T} \sum_{k=1}^{K}\left(C_{k} \gamma_{\text {de_k }}\right) * P_{\text {de }}(t) \\
C_{\text {de_fuel }}=\sum_{t=1}^{T} a+b P_{\text {de }}(t)+c P_{\text {de }}(t)^{2} \\
C_{\text {de_start }}=\alpha * n_{\text {de }}
\end{array}\right. \\
& C_{\text {grid_cost }}=\left\{\begin{array}{c}
C_{\text {grid_price }}=\sum_{t=1}^{T} \text { price }(t) * P_{\text {grid }}(t) \\
C_{\text {grid_en }}=\sum_{t=1}^{T} \sum_{i=1}^{K} \sum_{k}\left(C_{k} \gamma_{\text {grid_k }}\right) *\left|P_{\text {grid }}(t)\right|
\end{array}\right.
\end{aligned}
$$

where $C_{\text {de_cost }}$ is the COC of DE, which includes operation and maintenance $\operatorname{cost} C_{\text {de_om, fuel cost }}$ $C_{\text {de_fuel, }}$ environmental pollution control cost $C_{\text {de_en, }}$ and start-up cost $C_{\text {de_start }} ; C_{\text {grid_cost }}$ is the COC of main grid connect-line power, which includes the electricity $\operatorname{cost} C_{\text {grid_price }}$ produced by the power exchange between the main grid and the MG, and environmental pollution control cost $C_{\text {grid_en }} ; P_{\mathrm{de}}(t)$ and $P_{\text {grid }}(t)$ are, respectively, the power output of DE and the connect line of the main grid at time $t ; K_{\text {om_de }}$ is the operation cost coefficient of the DE unit; $\gamma_{\text {de_k }}$ and $\gamma_{\text {grid_k }}$ are the emissions of type $k$ pollutants generated by the operation of $\mathrm{DE}$ and the connect line of the main grid; and $C_{k}$ is the cost for handing type $k$ pollutants. $a, b, c$ are the fuel coefficients of DE, $\alpha$ is the cost of each start for DE, $n_{\mathrm{de}}$ is the number of start-up times of DE in one cycle, and price $(t)$ is the TOU price at time $t$ of the main grid side.

The constraint conditions for the source-grid-load level are

1. Upper and lower limit constraints of DE power output:

$$
P_{\mathrm{de}}^{\min } \leq P_{\mathrm{de}}(t) \leq P_{\mathrm{de}}^{\max }
$$

2. Climbing power limit of DE:

$$
P_{\mathrm{de}}^{\text {down }} \leq\left|P_{\mathrm{de}}(t)-P_{\mathrm{de}}(t-1)\right| \leq P_{\mathrm{de}}^{\text {up }}
$$

3. Upper and lower output limits of the main grid side:

$$
P_{\text {grid }}^{\min } \leq P_{\text {grid }}(t) \leq P_{\text {grid }}^{\max }
$$

4. Power balance equation:

$$
P_{\text {grid }}(t)+P_{\text {de }}(t)=P_{\text {load }}^{\prime}(t)
$$

where $P_{\mathrm{de}}^{\max }$ and $P_{\mathrm{de}}^{\min }$ are, respectively, the maximum and minimum power output of a DE unit; $P_{\mathrm{de}}^{\mathrm{up}}$ and $P_{\mathrm{de}}^{\text {down }}$ are the maximum and minimum climbing power of a DE unit; and $P_{\text {grid }}^{\max }$ and $P_{\text {grid }}^{\min }$ are, respectively, the maximum and minimum power output of the connect line of the main grid. 


\subsection{Dispatch Strategy for the Source-Grid-Load Level Under Isolated Grid}

The main network cannot provide energy support to the load when the MG is operating in an isolated grid state. Since the DGs in the MG cannot meet the load demand within the output range, load shedding will be used to ensure the power supply for significant loads [19]. Therefore, it is necessary to consider the economy of the operation and the reliability of the load in the MG economic dispatch of an isolated grid.

The objective functions of the source-grid-load level under isolated network operation find the minimum COC of DEs $f_{5}$ and the highest load reliability $f_{6}$, namely, the lowest load loss rate.

$$
f_{5}=\min \left[C_{\text {de_cost }}\right]
$$

The COC of DEs is the same as that in Section 2.4:

$$
f_{6}=\min \left[\left(\sum_{t=1}^{T} P_{\text {loss }}(t) / P_{\text {load }}(t)\right) / T\right]
$$

where $P_{\text {loss }}(t)$ is the loss of load at time $t$.

The constraint conditions are the same as in the grid-connected state.

\section{Solution Method and Simulation Parameters}

\subsection{Solution Method}

In this paper, the Monte Carlo simulation algorithm [20] was used to solve the load-level model, and the MPSO algorithm [21] was used to solve the models of the source-load level and source-grid-load level. A series of noninferior solution sets, called Pareto Fronts, can be obtained by using the MPSO algorithm [22].

The algorithm steps of MPSO optimization are basically the same as those of the standard particle swarm optimization (PSO) algorithm. Usually, the MPSO optimization algorithm steps are as follows:

1. Initializing the particle swarm. $M$ is the population size, $D$ is the particle dimension, and $K$ is the number of population evolution iterations; the position $x_{i d}$ and velocity $v_{i d}$ of each particle $(i=1,2 \cdots, M, d=1,2 \cdots, D)$ are randomly initialized.

2. Calculating the fitness values of particles.

3. Calculating the particle's individual optimum $P_{i}$ and global historical optimum $P_{g}$.

4. Selecting the new optimal value by comparing the function values of the maximum or minimum fitness functions.

5. Updating the particle velocity and position according to the following Equation (20) and Equation (21), respectively. If a dimension of the particle exceeds the boundary, the dimension data are re-initialized.

$$
\begin{gathered}
v_{i d}=w * v_{i d}^{k}+c_{1} * r_{1}\left(P_{i d}^{k}-x_{i d}^{k}\right)+c_{2} * r_{2}\left(P_{g d}^{k}-x_{i d}^{k}\right) \\
x_{i d}^{k+1}=x_{i d}^{k}+v_{i d}^{k+1}
\end{gathered}
$$

In the equations above, $w$ is inertia weight; $k$ is the number of iterations; $c_{1}$ and $c_{2}$ are nonnegative constants, called acceleration factors; $r_{1}$ and $r_{2}$ are random numbers distributed in the $[0,1]$ interval; $P_{i d}^{k}$ is the individual optimum value of the dimension $d$ at iteration $k$; and $P_{g d}^{k}$ is the global historical optimum value of the dimension $d$ at iteration $k, k=1,2,3 \ldots, K$.

6. Screening the noninferior solutions in the current particle swarm, adding the elite set, and eliminating the inferior solutions in the elite set.

7. If the termination condition is satisfied, the loop is completed; otherwise, we return to Step 2. 
The final elite set is the noninferior solution set obtained by the MPSO algorithm, which is also the goal we need to achieve.

After obtaining these noninferior solution sets, the fuzzy membership function [23] is employed to select the appropriate final solution. Consider a Pareto optimal solution $x_{j}$ in the Pareto Front; its satisfactory degree for the $l$ th subobjective function can be measured as follows:

$$
\mu_{l}^{j}=\frac{f_{l}^{\max }-f_{i}\left(x_{j}\right)}{f_{l}^{\max }-f_{l}^{\min }}
$$

where $f_{l}^{\max }$ and $f_{l}^{\min }$ denote the maximum and minimum value of the $l$ th subobjective function. Therefore, $\mu_{l}^{j}$ ranges from 0 to 1 .

The overall satisfactory degree $x_{j}$ to all objective functions can then be evaluated as follows:

$$
\mu^{j}=\frac{\sum_{l=1}^{L} \mu_{l}^{j}}{\sum_{j=1}^{J} \sum_{l=1}^{L} \mu_{l}^{j}}
$$

where $J$ and $L$ denote numbers of Pareto solutions and subobjectives, respectively. A higher value of $\mu^{j}$ means that the solution is better.

A flow chart of the hierarchical joint economic dispatching strategy for an MG and the main grid with load level, source-load level, and source-grid-load level is shown in Figure 5. Most of the input parameters for the MPSO were derived from [24].
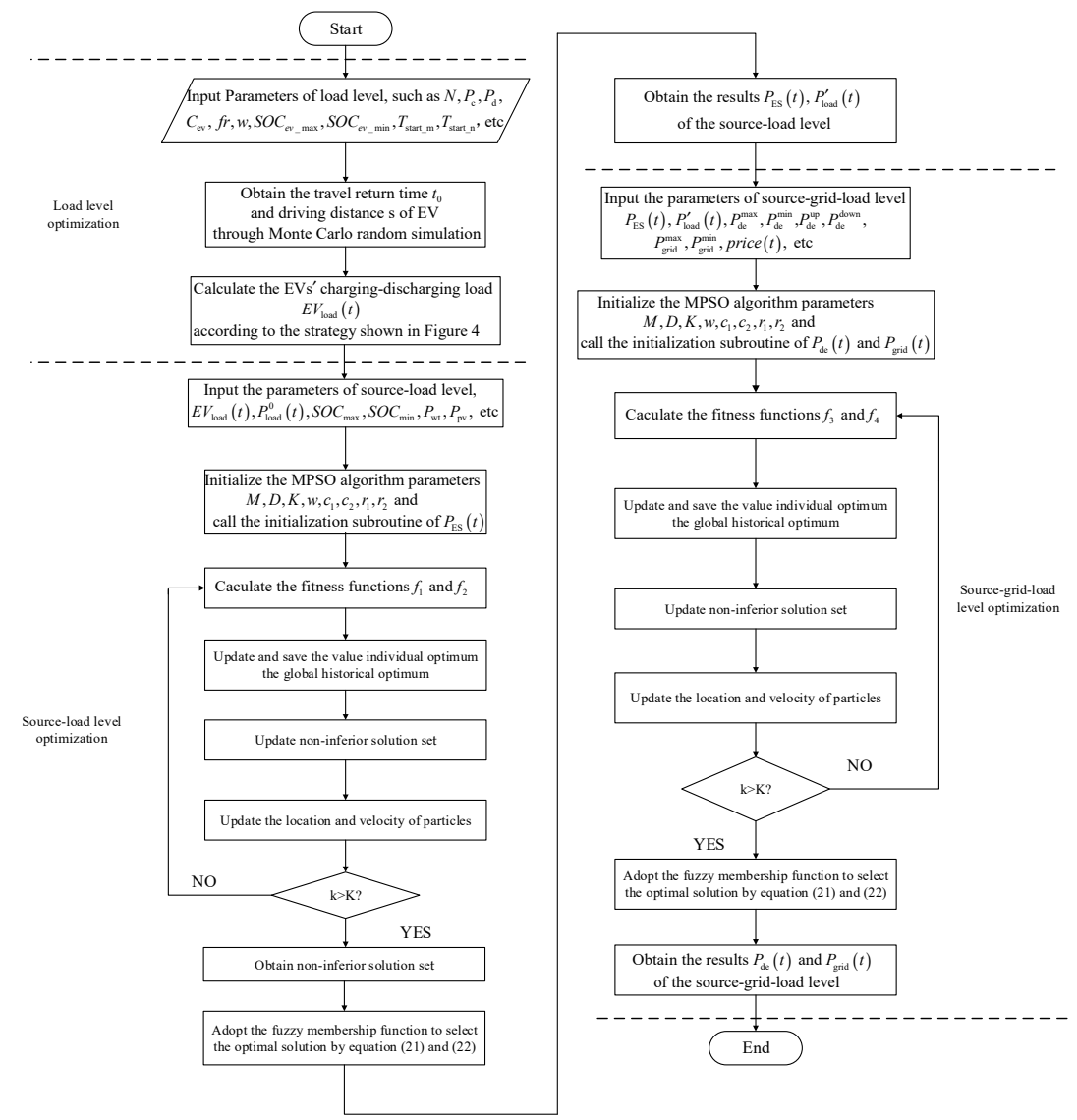

Figure 5. Flow chart of the MG multiobjective hierarchical joint economic dispatching strategy. 


\subsection{Simulation Parameters}

For a practical MG system in the central region of China $\left(114.36^{\circ} \mathrm{E}, 30.54^{\circ} \mathrm{E}\right)$, the average irradiance is $3.851 \mathrm{kWh} /\left(\mathrm{m}^{2} \times \mathrm{d}\right)$, and the average wind speed is about $3.4 \mathrm{~m} / \mathrm{s}$. The WT and PV output were generated randomly by the Monte Carlo algorithm using the previous model. The MG system contains $700 \mathrm{EVs}$ with a capacity of $24 \mathrm{kWh}$, a PV unit with a capacity of $1 \mathrm{MW}$, a WT with a capacity of $0.7 \mathrm{MW}$, two DEs with capacities of $0.6 \mathrm{MW}$ and $0.8 \mathrm{MW}$, and a lead-acid battery with a capacity of $1 \mathrm{MW}$ as an ES unit. The relevant technical parameters of the EVs were derived from [25]. The system deems that PV modules and WT are considered clean energy once installed, and there is no additional cost during use.

In this paper, a day-ahead economic dispatch is adopted for the MG system, with time intervals of one hour. The main grid price adopts the TOU method. The TOU price data are shown in Figure A1 of Appendix A. In Appendix A, the operation parameters of EVs, ES, DE, and the main grid connect line are shown in Table A1, and the types of pollutants produced in operation and the cost of pollutant control [16] are shown in Table A2.

\section{Results and Analysis}

\subsection{Results and Analysis of Load Level Optimization}

The Monte Carlo simulation algorithm was used to simulate the orderly charging-discharging load of EVs of different scales. The results obtained and the daily load curves of the MG are shown in Figure 6.

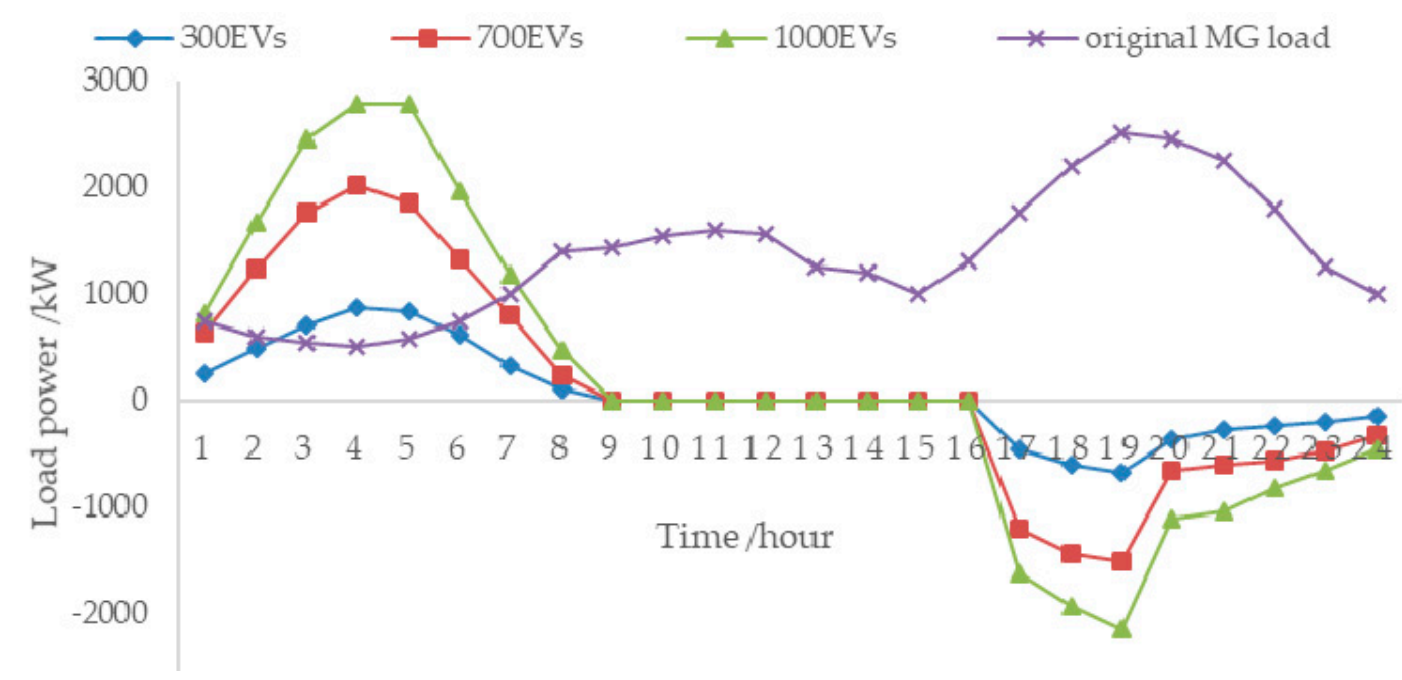

Figure 6. Orderly charging-discharging load curves of EVs with different scales.

From Figure 6, it can be seen that the original load of the MG began to peak at 8:00, and the charging loads of different scales of EVs almost completely finished charging and left the MG system before the early peak load appeared. From 9:00 to 16:00, the EVs are neither charged nor discharged, which is more in line with the user's driving habits. The EV user ends the day's journey and returns to the MG system to participate in discharging to support the peak of power consumption after 17:00.

Taking $700 \mathrm{EVs}$ for instance, the optimized afterload curve formed by superposition with the original load of the MG is shown in Figure 7. From the optimized load curve, it can be seen that the orderly charging-discharging behavior of the EV group has achieved the effect of "peak shaving and valley filling" to some extent. EV charging is concentrated from 1:00 to 8:00, while the MG load is in a low state and there are low electricity prices, which can save charging costs. EV discharging at the load state of the evening peak can alleviate a shortage of electricity at the evening peak, but also gain discharge subsidies. 


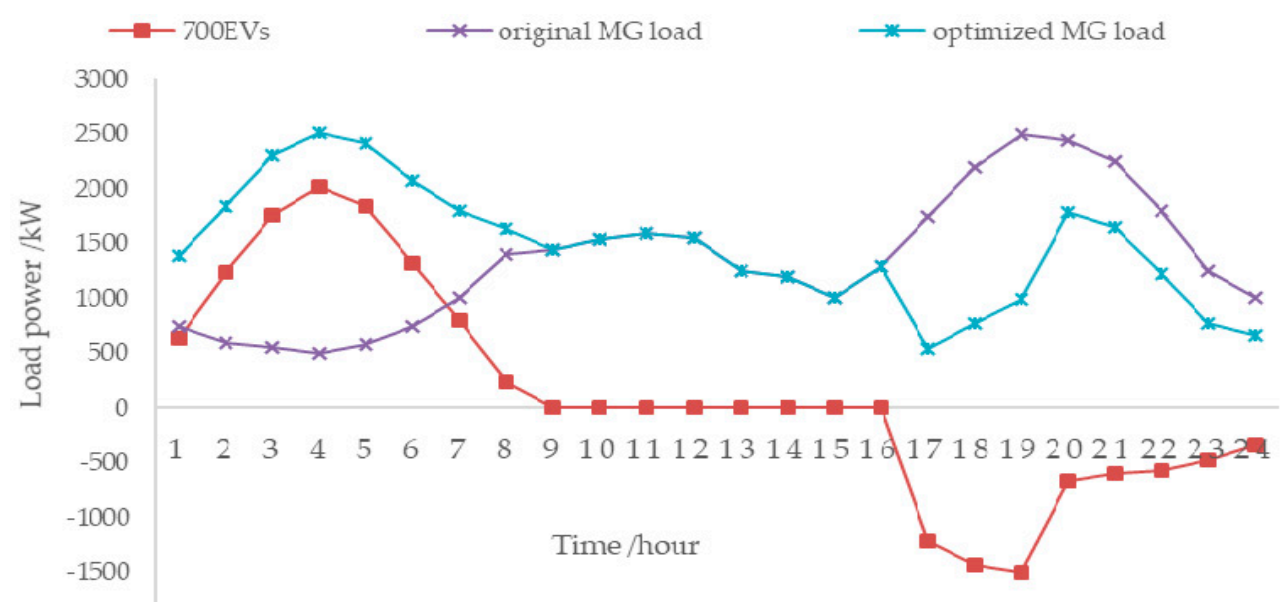

Figure 7. The optimized afterload curve.

\subsection{Results and Analysis of Source-Load Level Optimization}

By substituting the optimized load results of the load level into the source-load level model, the Pareto Front for the COC of ES and the average MG net load rate in the dispatching cycle were obtained through the MPSO algorithm as shown in Figure 8. It can be seen that the distribution of the Pareto solution is relatively uniform: the COC of the ES unit is distributed between 260¥and 440¥, and the average net load rate is between $40.8 \%$ and $42.2 \%$. Using the fuzzy membership function method described in Section 3.1, we took $(41.25 \%, 308.9)$ as the final compromise optimal solution for discussion and analysis, and the solution was substituted into the next level for calculation.

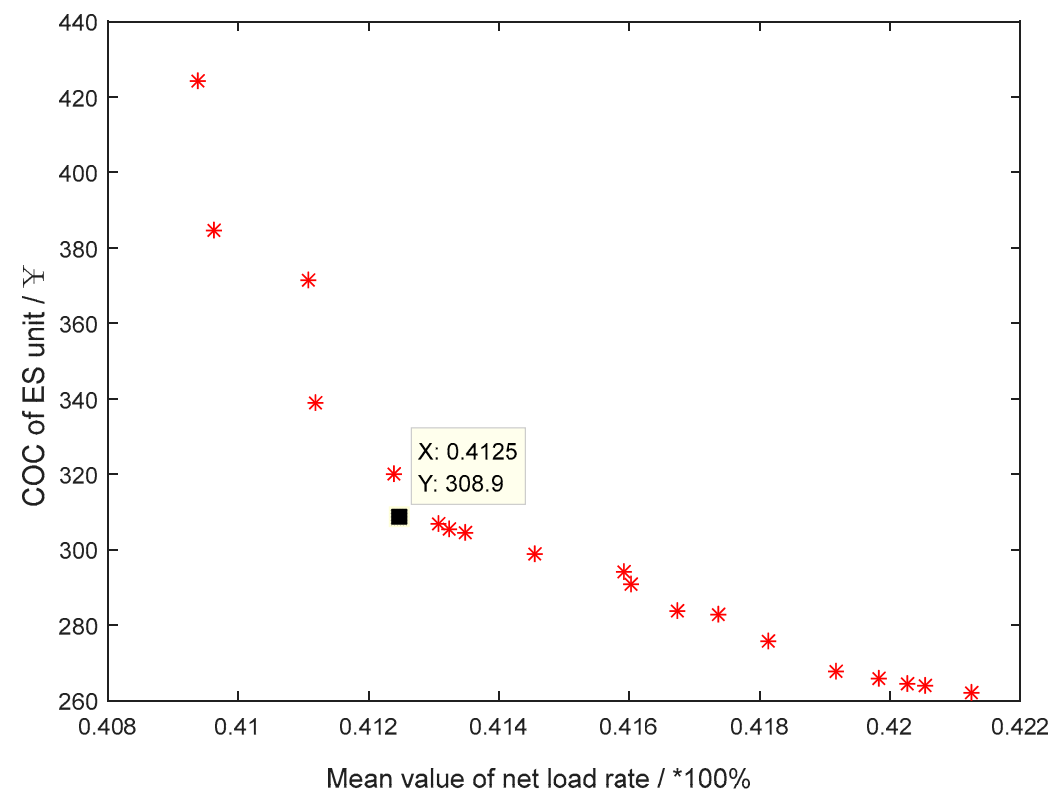

Figure 8. Pareto front of source-load level.

The output curve diagram of each unit at the source-load level obtained by the MPSO algorithm is shown in Figure 9. It can be seen that the ES unit replenishes a small amount of electricity at a low electricity price in the early morning, and then discharges rapidly when the WT and PV power output is insufficient to support the load in the MG. At the same time, in order to ready absorb the surplus renewable energy as much as possible when WT and PV output are excessive, the ES unit discharges to the lowest SOC at about 12:00. Then, the ES absorbs the surplus renewable energy from 12:00 to 18:00, so as to reduce the impact of renewable energy on the main grid at the third level, and at the 
same time to provide electricity for the subsequent peak load of the MG. From 18:00 to 24:00, the ES unit releases the electricity absorbed during the day to support the MG load. From the net load curve, it can be seen that from 12:00 to 18:00, the MG load demand is completely met, and part of the surplus WT and PV output power in this period is absorbed by the ES. The surplus WT and PV power that is not fully absorbed by the ES will be sold to the main grid at the source-grid-load level for profit.

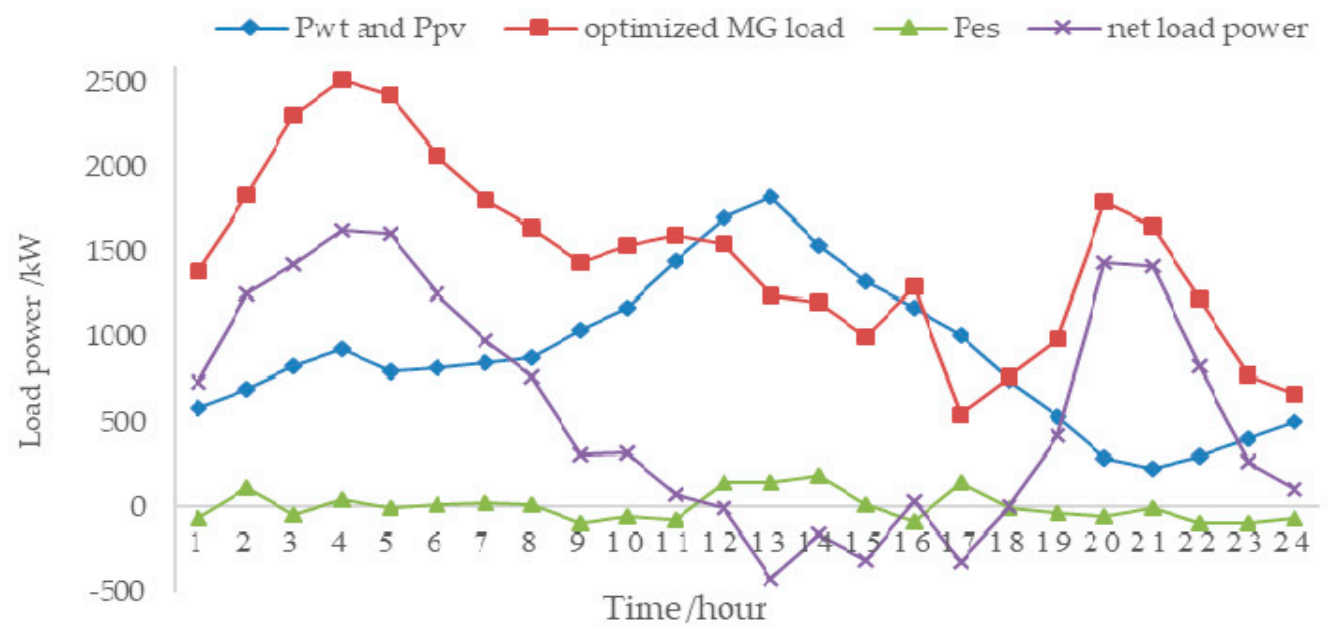

Figure 9. Pareto front of source-load level.

The SOC curve of the ES unit in one cycle is shown in Figure 10. It can be seen that the SOC of the ES unit in the dispatching cycle has been maintained within a reasonable range. Combining this with Figure 9, we see that the SOC of the ES unit increases during the period when the output of WT and PV is greater than the MG load. However, the ES unit does not absorb all the surplus renewable energy from 12:00 to 18:00 due to its limitation of charging power. Therefore, the surplus energy of this part will be merged into the main grid at the source-grid-load level.

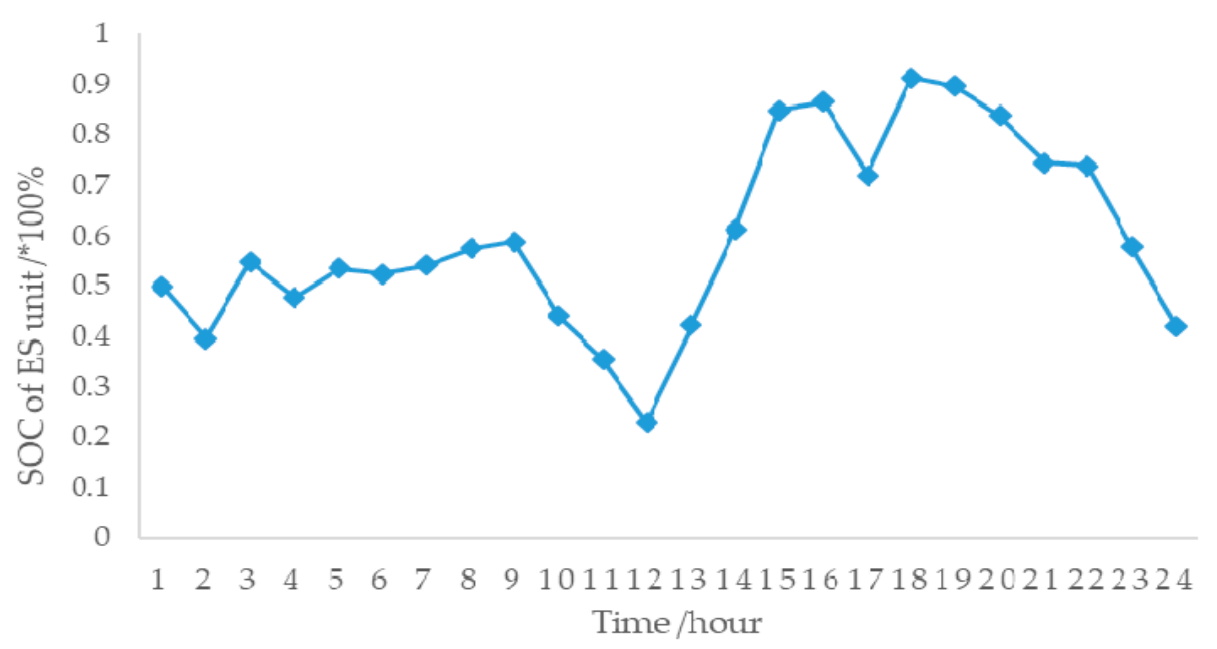

Figure 10. SOC of ES in one cycle.

\subsection{Results and Analysis of Source-Grid-Load Level Optimization}

The results of the net load power and ES output power of the MG optimized by the source-load level were substituted into the source-grid-load level, which is still solved by the MPSO algorithm. The Pareto Front with the optimal COC and connect-line power fluctuation of this level was obtained as shown in Figure 11. It can be seen that the distribution of the Pareto solution is relatively uniform: the COC of this level is between 16,000¥and 30,000¥, and the power fluctuation of the main grid 
connect line is between $6500 \mathrm{~kW}$ and $7500 \mathrm{~kW}$. The compromise optimal solution $\left(2.037 \times 10^{4}, 6755\right)$ in Figure 11 was selected for discussion.

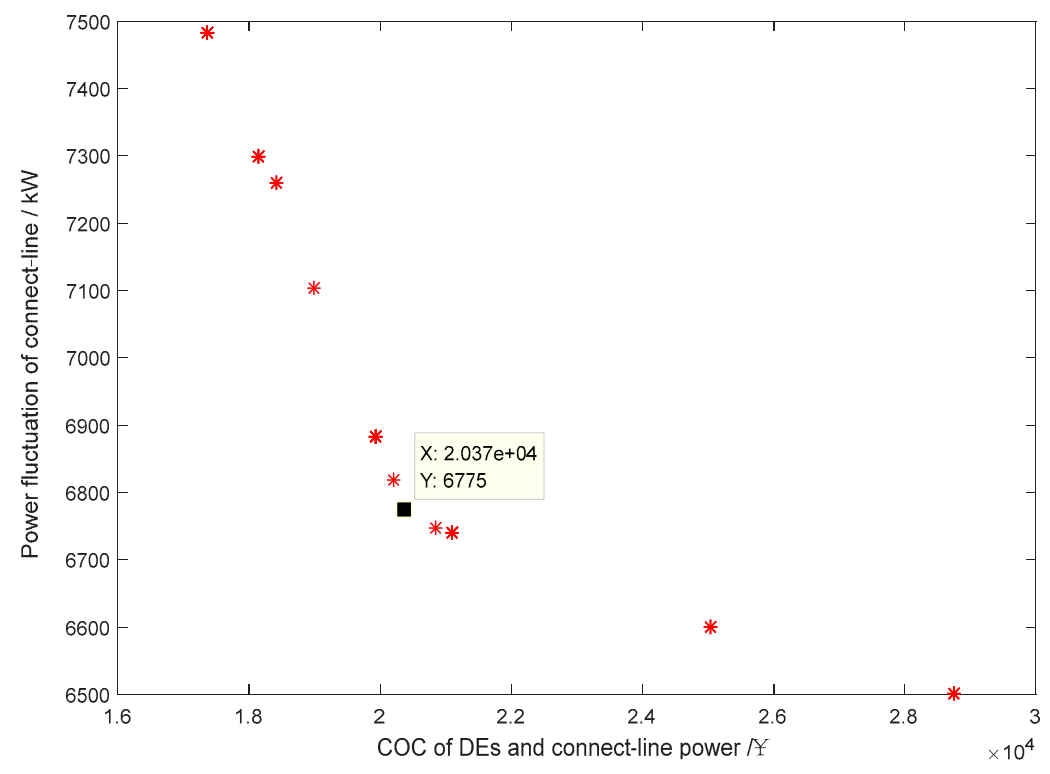

Figure 11. Pareto front of the source-grid-load level.

The output power curve for each unit of the source-grid-load level obtained by the MPSO algorithm is shown in Figure 12. As observed from the output power curves, the MG purchases more electricity from the main network than two DEs' output power when the net load is positive and the electricity price is low in the morning, such as from 1:00 to 8:00, to reduce the economic cost of MG operation. When the net load is less or even zero, such as from 9:00 to 12:00 and from 23:00 to 24:00, the DE will continue to generate electricity due to the high grid electricity price during this period, and the profit of selling this electricity from the MG to the main grid can be obtained. When the net load is negative, for instance, from 13:00 to 18:00, the surplus WT and PV power not fully absorbed by the ES unit is sold to the main grid by the MG to obtain a net income. When the net load is positive, such as from 19:00 to 22:00 at night, due to the high COC of the two DE, the power source of the MG load is still mainly supported by the main grid though the electricity price is at the peak value during this period.

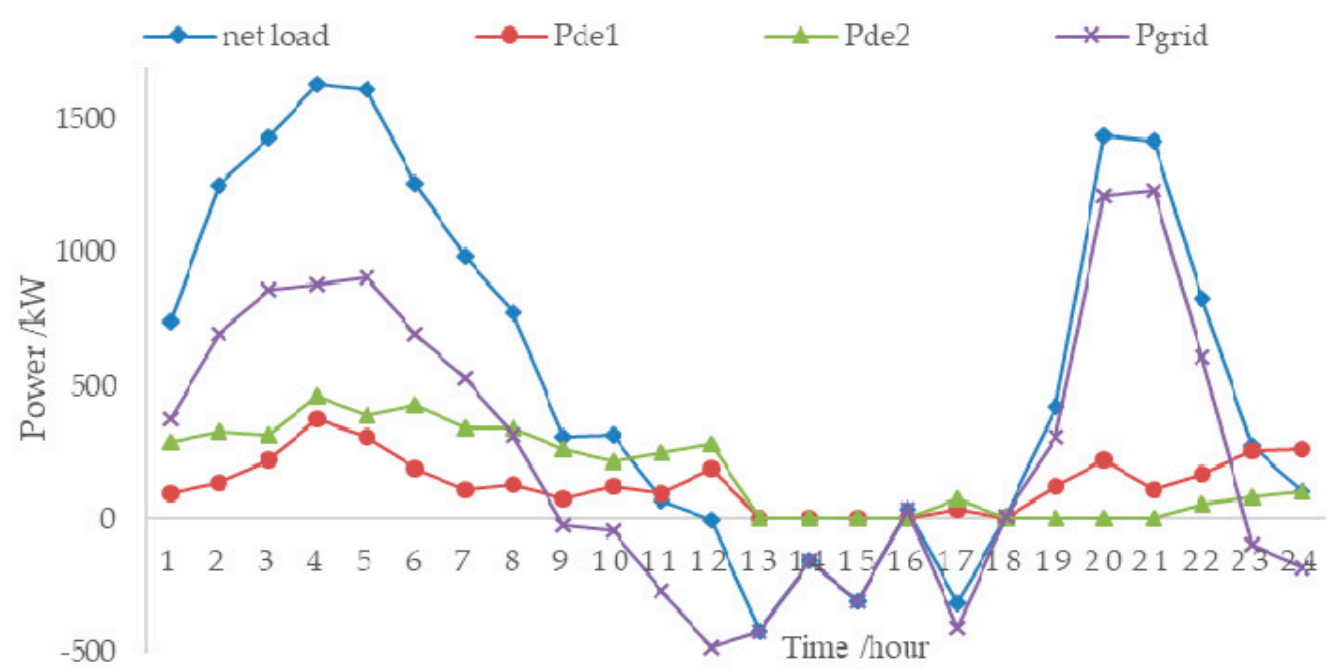

Figure 12. Output of each unit at the source-load-grid level. 


\subsection{Comparison and Analysis}

4.4.1. Analysis of the Results of the Economic Dispatching Operation of a Multiobjective Hierarchical MG with Random Charging of EVs

The random charging of EVs generally follows the user's travel rules, namely, the user starts charging the EV immediately upon returning home after finishing their trip. The Monte Carlo simulation algorithm was used to simulate the random charging load of 700 EVs as shown in Figure 13.

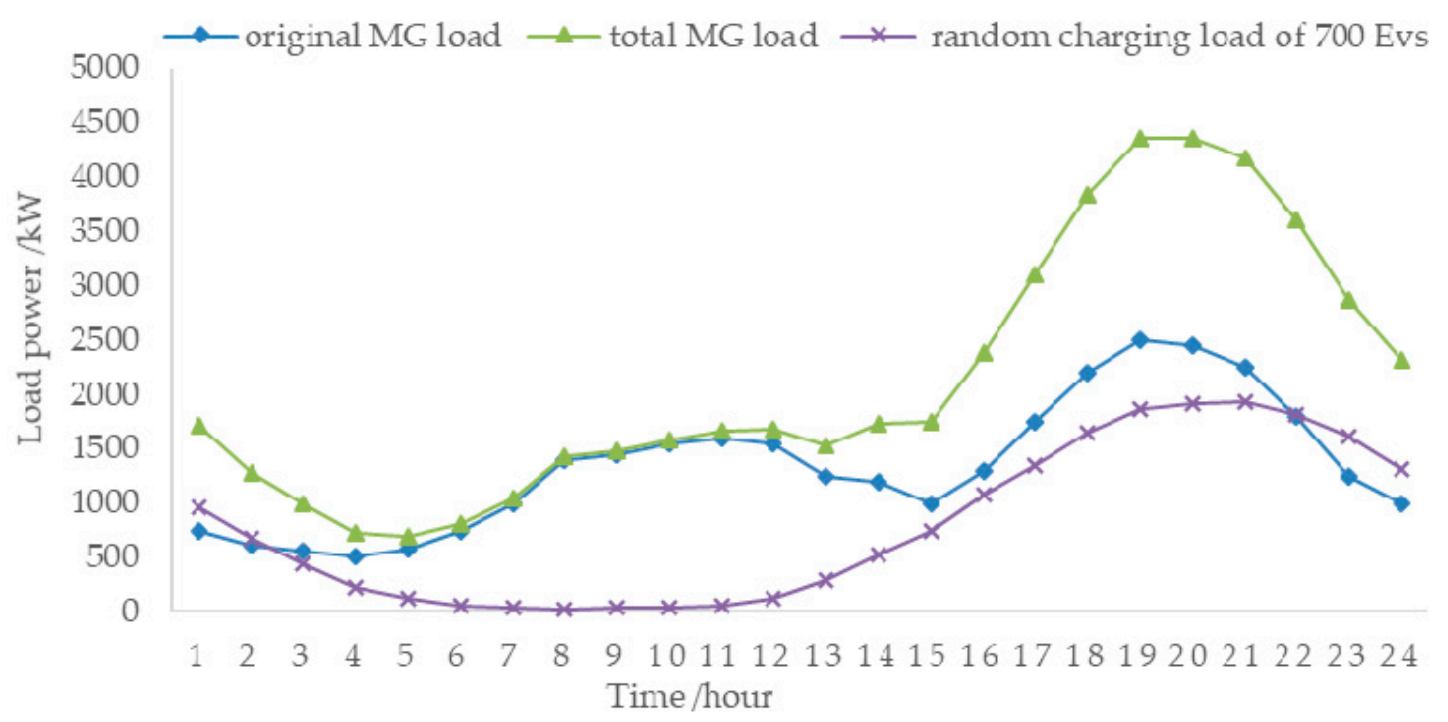

Figure 13. Random EV charging load curve.

The random charging load of EVs was simulated according to the scheduling strategy of the source-load level and the source-grid-load level mentioned above. The mean values of 20 groups of Pareto solutions obtained by simulation were compared with those obtained from the source-grid-load level under an orderly EV charging-discharging strategy, as shown in Table 1. From the analysis in Table 1, it can be seen that the COC of the ES unit is not much different between the strategy of EV random charging and EV orderly charging-discharging due to the limitation of the ES capacity and output power. Since the disorderly charging load of EVs is concentrated in the period of higher electricity price, the COC of DEs and the COC and power fluctuation of the connect line are increased by $90.42 \%, 131.68 \%$, and $23.40 \%$ compared with orderly charging-discharging, respectively. Further, the increase in connect line operation costs is greater than that of DEs since EVs are mostly charged during a period of high electricity prices. In summary, the economics and safety of MG dispatching under EV orderly charging-discharging are better than those under EV disorderly charging.

Table 1. Comparison of simulation results.

\begin{tabular}{ccc}
\hline Items & Disorderly Charging & Orderly Charging-Discharging \\
\hline COC of ES unit $/ ¥$ & 310.53 & 308.9 \\
COC of DEs $/ ¥$ & 13,794 & 7243.829 \\
COC of connect-line power $/ ¥$ & $30,414.38$ & $13,127.618$ \\
Power fluctuation of connect line $/ \mathrm{kW}$ & 8336 & 6755 \\
\hline
\end{tabular}

4.4.2. Analysis of the Results of the Economic Dispatching Operation of a Multiobjective Hierarchical MG under Isolated Grid Operation

The load level and source-load level dispatching strategies under isolated grid operation are the same as those described in Sections 2.3 and 2.4 above. The compensation cost for load shedding is uniformly $1.4788 ¥$ [19]. By substituting the net load result obtained from the source-load level 
into the isolated grid operation state and solving it using the MPSO algorithm, the Pareto Front of the mean load shedding rate and also the DE COC can be obtained. Through calculating the mean values of 20 groups of Pareto solutions obtained by the simulation, the DE COC and load shedding compensation costs under isolated grid operation are shown in Table 2. Compared with the results of grid-connected operation optimization, the COC of DE and the MG system are respectively increased by $266.7 \%$ and $60.33 \%$ under the isolated grid. It can be seen that the economy of connected-grid operation is better than that of isolated grid operation in the MG system setup of this paper.

Table 2. Comparison of simulation results.

\begin{tabular}{ccc}
\hline Item & Isolated Grid & Connected Grid \\
\hline COC of DE $/ ¥$ & $26,564.93$ & 7243.8290 \\
COC of connect-line power $/ ¥$ & $/$ & $13,127.618$ \\
Compensation cost of loss load $/ ¥$ & 6095.94 & $/$ \\
Total COC $/ ¥$ & $32,660.87$ & $20,371.447$ \\
\hline
\end{tabular}

\section{Conclusions}

In this paper, a multiobjective hierarchical dispatching strategy with load level, source-load level, and source-grid-load level was proposed to solve the MG economic dispatching problem. The strategy fully considers the operating characteristics of the dispatching units involved at each level, and takes into account the economic, environmental, and security benefits of all parties. On the basis of meeting the MG load demand, the multi-win situation of low economic cost, environmental benefits, and high security and reliability of the MG system can be achieved. Meanwhile, the proposed strategy was compared and analyzed for two kinds of operation situations, which all verified the scientificity and effectiveness of the strategy.

The wind speed, light intensity, and historical load of a typical day are simply used to simulate the output of $\mathrm{WT}, \mathrm{PV}$, and the MG original load in this paper. The forecasting data required by the experiment were obtained without considering the output uncertainty of wind, solar, and load. Therefore, how to synthetically consider the uncertain impact of wind and solar output and load on the MG system might be regarded as the next research topic.

Author Contributions: Conceptualization, H.H. and M.X.; methodology, Y.X., J.T. and G.Z.; validation, H.H. and M.X.; formal analysis, M.X. and H.H.; investigation, H.H., M.X., P.L. and T.X.; writing一 original draft preparation, M.X. and H.H.; writing-review and editing, H.H. and M.X.

Funding: This research was funded by the National Natural Science Foundation of China (51777146) and National Natural Science Foundation for Young Scientists of China (51707139).

Conflicts of Interest: The authors declare no conflict of interest.

\section{Nomenclature}

$\begin{array}{ll}\text { Abbreviations } & \\ \text { MG } & \text { Microgrid } \\ \text { COC } & \text { comprehensive operating cost } \\ \text { ES } & \text { energy storage } \\ \text { EV } & \text { electric vehicle } \\ \text { TOU } & \text { time of use } \\ \text { DE } & \text { diesel engine } \\ \text { DG } & \text { distributed generation } \\ \text { CHP } & \text { Combined Heat and Power } \\ \text { WT } & \text { wind turbines } \\ \text { PV } & \text { photovoltaics } \\ \text { SOC } & \text { state of charge } \\ \text { MPSO } & \text { Multiobjective Particle Swarm Optimization }\end{array}$




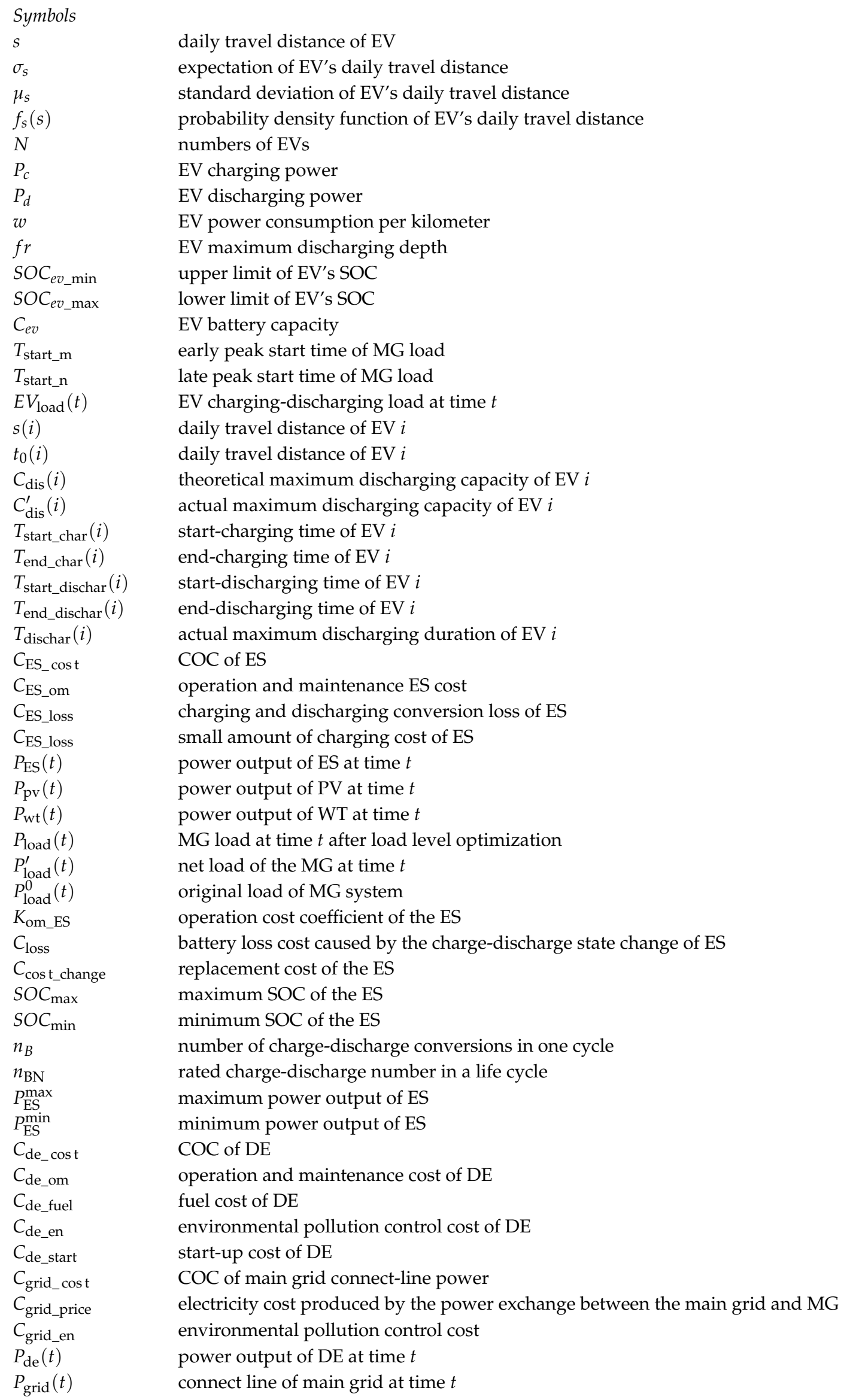




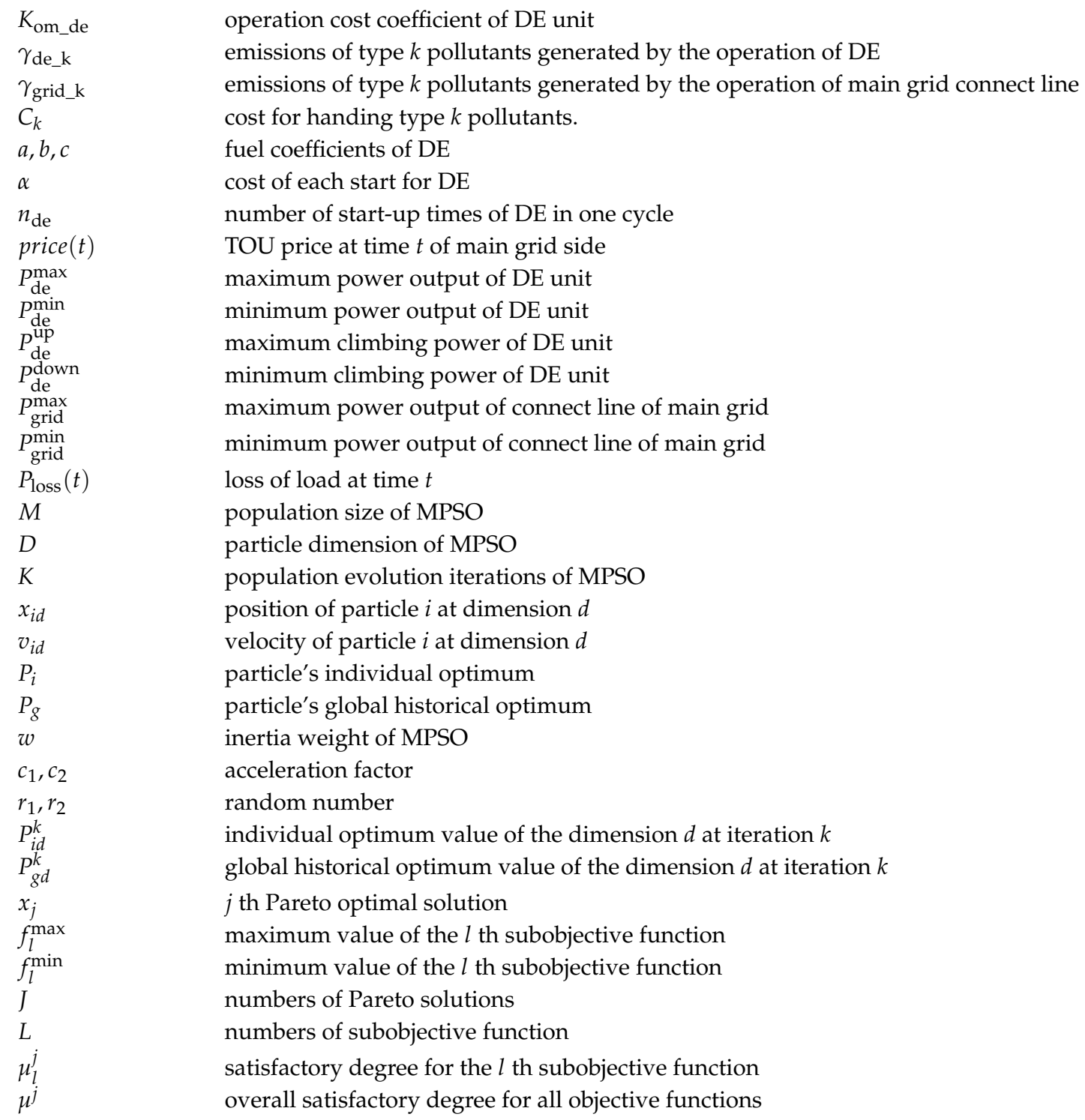

\section{Appendix A}

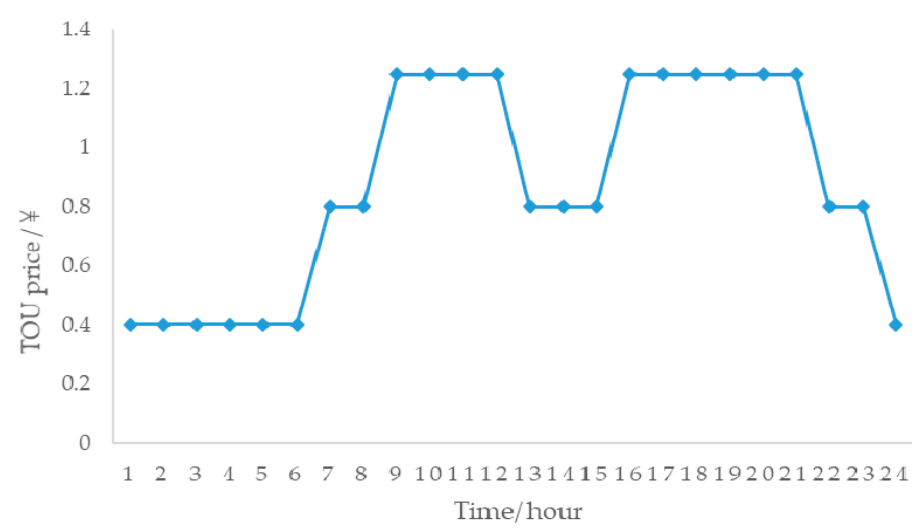

Figure A1. The TOU price. 
Table A1. Operating parameters.

\begin{tabular}{cccccc}
\hline \multirow{2}{*}{ Operation Parameters } & \multicolumn{5}{c}{ Items } \\
\cline { 2 - 6 } & EV & ES & DE1 & DE2 & Main Grid Connect Lines \\
\hline Maximum output/kW & 4 & 250 & 600 & 800 & 2000 \\
Minimum output/kW & -4 & -250 & 0 & 0 & -600 \\
Maximum climb/kW & $/$ & $/$ & 100 & 150 & $/$ \\
Minimum climb/kW & $/$ & $/$ & -100 & -150 & $/$ \\
Charging efficiency & 0.9 & 0.9 & $/$ & $/$ & $/$ \\
Discharge efficiency & 0.9 & 0.9 & $/$ & $/$ & $/$ \\
Maximum SOC & 0.9 & 0.9 & $/$ & $/$ & $/$ \\
Minimum SOC & 0.3 & 0.2 & $/$ & $/$ & \\
$K_{\mathrm{om}} /(Y=/ \mathrm{kW})$ & $/$ & 0.1040 & 0.236 & 0.236 & \\
\hline
\end{tabular}

Table A2. Pollutant emission coefficient and disposal cost.

\begin{tabular}{ccccc}
\hline \multicolumn{2}{c}{ Types of Pollutants } & $\mathrm{CO}_{2}$ & $\mathrm{SO}_{2}$ & $\mathrm{NO}_{x}$ \\
\hline Cost of Pollutant Disposal/ $(\mathrm{Y}=/ \mathrm{kg})$ & 0.210 & 14.824 & 62.964 \\
\hline \multirow{2}{*}{$\begin{array}{c}\text { Coefficient pollutant } \\
\text { emission/ }(\mathrm{g} / \mathrm{kWh})\end{array}$} & $\mathbf{P V}$ & 0 & 0 & 0 \\
\cline { 2 - 5 } & $\mathbf{W T}$ & 0 & 0 & 0 \\
\cline { 2 - 5 } & Main grid & 889 & 0.206 & 9.89 \\
\hline
\end{tabular}

\section{References}

1. Katiraei, F.; Iravani, M.R. Power management strategies for a microgrid with multiple distributed generation units. IEEE Trans. Power Syst. 2006, 21, 1821-1831. [CrossRef]

2. Huang, W.T.; Yao, K.C.; Wu, C.C.; Chang, Y.R.; Lee, T.D.; Ho, Y.H. A three-stage optimal approach for power system economic dispatch considering microgrids. Energies 2016, 9, 976. [CrossRef]

3. Wang, L.J.; Xu, H.L.; Wang, G. Economic dispatch model for microgrid considering power characteristics of distributed generators. Autom. Elec. Power Syst. 2016, 11, 31-38. [CrossRef]

4. Augustine, N.; Suresh, S.; Moghe, P.; Sheikh, K. Economic dispatch for a microgrid considering renewable energy cost functions. In Proceedings of the 2012 IEEE PES Innovative Smart Grid Technologies, Washington, DC, USA, 16-20 January 2012.

5. Ramabhotla, S.; Bayne, S.; Giesselmann, M. Economic dispatch optimization of mg in islanded mode. In Proceedings of the Energy and Sustainability Conference, Farmingdale, NY, USA, 23-24 October 2014.

6. Wu, X.; Wang, X.L.; Wang, J.X.; Bie, Z.H. Economic generation scheduling of a microgrid using mixed integer programming. Proc. CSEE 2013, 28, 1-8. [CrossRef]

7. Wu, H.; Wang, Y.S. Economic dispatch of microgrid using intelligent single particle optimizer algorithm. Power Syst. Prot. Control 2016, 20, 43-49. [CrossRef]

8. Wang, X.H.; Qian, W.S. A new scheduling method of microgrid based on improved pso algorithm. Power Syst. Clean Energy 2017, 7, 53-57.

9. Wang, Y.S.; Song, Y.Y.; Wu, H.; Yi, J.B. Security and economic dispatch of source/load for micro-grid based on Tabu search algorithm. Power Syst. Prot. Control 2017, 20, 21-27. [CrossRef]

10. Chen, J.; Yang, X.; Zhu, L.; Zhang, M.X.; Li, Z.K. Microgrid multi-objective economic dispatch optimization. Proc. CSEE 2013, 19, 57-66. [CrossRef]

11. Mao, M.Y.; Ji, M.H.; Dong, W. Multi-objective economic dispatch model for a microgrid considering reliability. In Proceedings of the 2nd International Symposium on Power Electronics for Distributed Generation Systems, Hefei, China, 12 August 2010.

12. Farzin, H.; Fotuhi-Firuzabad, M.; Moeini-Aghtaie, M. A stochastic multi-objective framework for optimal scheduling of energy storage systems in microgrids. IEEE Trans. Smart Grid 2017, 8, 117-127. [CrossRef]

13. Wang, J.; Wang, L.L.; Gou, Y.; Sun, L.H.; Guan, Z.J. Microgrid economic dispatch method considering electric vehicles. Power Syst. Prot. Control 2016, 17, 111-117. [CrossRef] 
14. Zhao, X.Y.; Wang, S.; Wu, X.H.; Liu, J. Coordinated control strategy research of micro-grid including distributed generations and electric vehicles. Power Syst. Technol. 2016, 12, 3732-3740. [CrossRef]

15. Li, J.; Niu, D.; Wu, M.; Wang, Y.; Li, F.; Dong, H. Research on battery energy storage as backup power in the operation optimization of a regional integrated energy system. Energies 2018, 11, 2990. [CrossRef]

16. Liu, H.T.; Ji, Y.; Zhuang, H.D.; Wu, H.B. Multi-objective dynamic economic dispatch of microgrid systems including vehicle-to-grid. Energies 2015, 8, 4476-4495. [CrossRef]

17. Zhang, H.C.; Hu, Z.C.; Song, Y.H.; Xu, Z.W.; Jia, L. A prediction method for electric vehicle charging load considering spatial and temporal distribution. Autom. Electr. Power Syst. 2014, 1, 13-20. [CrossRef]

18. Liu, H.; Ji, Y.; Zhuang, H.D.; Wu, H.B. Multi-objective economic dispatch of microgrid system considering electric vehicles. Trans. China Electrotech. Soc. 2014, s1, 365-373. [CrossRef]

19. Einan, M.; Torkaman, H.; Pourgholi, M. Optimized fuzzy-cuckoo controller for active power control of battery energy storage system, photovoltaic, fuel cell and wind turbine in an isolated micro-grid. Batteries 2017, 3, 23. [CrossRef]

20. Agrawal, S.; Panigrahi, B.K.; Tiwari, M.K. Multiobjective particle swarm algorithm with fuzzy clustering for electrical power dispatch. IEEE Trans. Evol. Comput. 2008, 12, 529-541. [CrossRef]

21. Jin, N.; Rahmat-Samii, Y. Advances in particle swarm optimization for antenna designs: Real-number, binary, single-objective and multiobjective implementations. IEEE Trans. Antennas Propag. 2007, 55, 556-557. [CrossRef]

22. Yang, Y.; Wu, J.F.; Zhu, X.B.; Wu, J.C. A hybrid evolutionary algorithm for finding pareto optimal set in multi-objective optimization. In Proceedings of the 2011 Seventh International Conference on Natural Computation, Shanghai, China, 26-28 July 2011.

23. Xu, Y.; Dong, Z.; Xiao, C.; Zhang, R.; Wong, K. Optimal placement of static compensators for multi-objective voltage stability enhancement of power systems. IET Gen. Trans. Dist. 2015, 9, 2144-2151. [CrossRef]

24. Yu, S.W. Case analysis and Application of MATLAB Optimization Algorithm, 1st ed.; Tsinghua University Press: Beijing, China, 2014; pp. 156-174.

25. Hou, H.; Ke, X.B.; Wang, C.Z.; Fan, H.; Lou, J.Y. Coordinated optimazation strategy for electric vehicles' charging and discharging in different regions. High Volt. Technol. 2018, 0222, 648-654. [CrossRef]

(C) 2018 by the authors. Licensee MDPI, Basel, Switzerland. This article is an open access article distributed under the terms and conditions of the Creative Commons Attribution (CC BY) license (http://creativecommons.org/licenses/by/4.0/). 